\title{
AVALIAÇÃO DO IMPACTO SONORO DA TERMOELÉTRICA NA ÁREA URBANA DO MUNICÍPIO DE HUMAITÁ-AM
}

\section{Sound of impact assessment in urban area of the thermal city of Humaitá-AM}

\author{
Fabiana Patrícia Silva \\ Universidade Federal do Amazonas \\ fabypaty72@gmail.com \\ Miqueias Lima Duarte \\ Universidade Federal do Amazonas \\ miqueiaseng@hotmail.com \\ Amazonino Lemos de Castro \\ Universidade Federal do Amazonas \\ alcastro@ufam.edu.br
}

Resumo: A poluição sonora é depois da poluição do ar e da água, o problema ambiental que afeta o maior número de pessoas. O crescimento rápido dos centros urbanos em consonância com a produção de barulhos decorrente das atividades desenvolvidas pela sociedade tem gradativamente diminuído a qualidade de vida da população. A usina termoelétrica que é responsável pela geração de eletricidade no município de Humaitá encontra-se instalada área urbana do município. Em função da falta de planejamento urbano adequado, o empreendimento fica instalada no centro da cidade, e no seu entorno é ocupado por área residencial. Este trabalho teve por objetivo avaliar o nível de impacto sonoro no entorno da área onde fica instalada a usina termoelétrica do município de Humaitá, no sul do estado do Amazonas. Foram coletados níveis de ruídos em 41 pontos amostrais no entorno do empreendimento termelétrico com uso de um decibelímetro digital. Os dados foram interpolados pelo método de krigagem e especializados para confecção cartográfica. Os resultados obtidos revelaram que na área de estudo os níveis de ruídos estão cerca de $10 \mathrm{~dB}$ acima dos valores estabelecidos pela legislação vigente, assim, gerando riscos à saúde da população que reside nesse local.

Palavras-chave: Poluição sonora, área de impacto sonoro, geotecnologia.

\begin{abstract}
Noise pollution is, after air and water pollution, the environmental problem affecting the largest number of people. The rapid growth of urban centers in line with the production of noises resulting from the activities developed by the society has gradually diminished the quality of life of the population. The thermoelectric power plant that is responsible for electricity generation in the municipality of Humaitá is installed urban area of the municipality. Due to the lack of adequate urban planning, the project is installed in the center of the city, and in its surroundings is occupied by residential area. This work aimed to evaluate the level of sound impact in the area where the thermoelectric plant of the municipality of Humaitá is installed in the south of the state of Amazonas. Noise levels were collected in 41 sampling points in the vicinity of the thermoelectric undertaking using a digital decibel meter. The data were interpolated by the Kriging method and specialized for cartographic preparation. The results showed that in the area of study noise levels are about 10 DB above the values established by current legislation, thus generating risks to the health of the population that resides in this location.
\end{abstract}

Keywords: Noise pollution, impact area, Geotechnology. 
AVALIAÇÃO DO IMPACTO SONORO DA TERMOELÉTRICA NA ÁREA URBANA DO MUNICÍPIO DE HUMAITÁ/AM

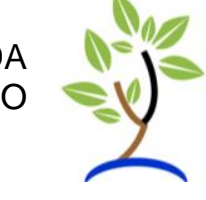

\section{INTRODUÇÃO}

No dia-a-dia o ser humano é exposto constantemente a diversos níveis ruídos, a audição não é poupada nem mesmo quando se está dormindo. Esses ruídos podem gerar muitos incômodos, tais como problemas de saúde e em casos mais extremos pode ocorrer até a perda de audição.

Fernandes (2011) cita que para a abordagem do tema Poluição Sonora, a primeira consideração a ser feita é a respeito da diferença entre um som, de qualidade agradável, para que os que apreciam uma boa sonoridade, e o ruído, causador de desconforto e de danos à saúde. Freitas e Freitas (2006) definiram poluição sonora como a emissão de ruídos que ultrapassem os níveis estabelecidos pela legislação, o que constitui um dos fatores de maior perturbação e danos à saúde humana.

No Brasil, quem estabelece os níveis de ruídos, definindo quando há poluição sonora ou não, é a Resolução do Conama (Conselho Nacional do Meio Ambiente), valendose dos padrões estabelecidos pela Associação Brasileira de Normas Técnicas/ABNT NBR $n^{\circ} 10.151$ de 2000 no qual avalia o nível de ruído em áreas habitadas, visando o conforto da comunidade.

O crescimento rápido dos centros urbanos vem acarretando o aumento dos níveis de ruídos emitidos, esse problema tem gradativamente diminuído a qualidade de vida das pessoas (Pereira e Laureano, 2015). Segundo Almeida et al. (2017), a poluição sonora como resultado das relações sociais, produzida pela sociedade tem crescido cada vez mais no espaço urbano. A produção de barulho perturbador que causa incômodos ao bem-estar é consequência da produção artificial dos grandes centros urbanos por meio das atividades desenvolvidas pela sociedade.

Existem diversos trabalhos relatando os problemas causados pela poluição sonora nas cidades brasileiras (Marchetti e Carvalho, 2011; Paz e Nannin, 2012; Soares et al. 2014; Bressane et al., 2015; Pereira e Laureano, 2015; Sousa, 2016; Tavares, 2016; Oliveira et al., 2018), ambos descrevem que a poluição sonora trata-se de um problema complexo, pois é produzida por diversas fontes e atinge a coletividade, e em muitas ocasiões fazem parte até mesmo da cultura local.

Em Curitiba/PR, Zannin et al. (2002) apuraram que as principais fontes de ruído causadores de incômodos são o trafego de veículos (73\%) e vizinhos (38\%). Na região de Pinheiros/SP Shoegima e Filho (2014) observaram que os índices de ruídos excedem os limites sonoros do zoneamento municipal. No interior do estado do Amazonas (Pauini), Almeida et al. (2017) relataram graves problemas de saúde em função da poluição sonora no perímetro urbano, em destaque os moradores que residem no entorno da usina termelétrica do município.

$\mathrm{Na}$ área urbana do município de Humaitá encontra-se instalado a usina termoelétrica que é responsável pela geração de eletricidade para o município. Em função da falta de planejamento urbano adequado, a termoelétrica fica instalada no centro da cidade, e no seu entorno é ocupado por área residencial. Logo, os moradores da região são expostos continuamente ao ruído emitido pela mesma. O que torna preocupante, pois a exposição continuada a certos níveis de ruídos pode causar sérios danos à saúde humana. 
AVALIAÇÃO DO IMPACTO SONORO DA TERMOELÉTRICA NA ÁREA URBANA DO MUNICÍPIO DE HUMAITÁ/AM

A

Segundo a Organização Mundial de Saúde (OMS), a poluição Sonora é, depois da poluição do ar e da água, o problema ambiental que afeta o maior número de pessoas, sendo perceptível o aumento do incômodo devido ao ruído e o prejuízo que isto tem causado ao homem no seu ambiental laboral e/ou ambiental (OMS, 2002).

De acordo com OMS (2012), níveis de ruído a partir de $50 \mathrm{~dB}$ o organismo começa a sentir os efeitos negativos, como a redução da produtividade, dificuldade de relaxamento, redução do poder de concentração. Segundo Pastore (2010) e Servinskas (2013), quando os níveis de ruído ultrapassam os $75 \mathrm{~dB}$, aumentam os riscos de infarto, infecções e outras doenças, em virtude do abalo da saúde mental.

Nem sempre quem vive exposto a certos níveis de ruídos conseguem identificar os malefícios causados por eles. E muitos chegam a pensar que de fato não há nenhuma consequência, entretanto Paulo Machado (2010) destaca que o fato de o organismo se adaptar ao barulho, ao ruído excessivo, não exclui os efeitos danosos.

A identificação e mapeamento dos níveis de ruídos nos centros urbanos é o primeiro passo na para planejamento adequado. De acordo com Garavelli et al. (2010), o mapa de ruído constitui-se como uma ferramenta adequada para estudo do problema, pois mostra a distribuição geográfica da poluição sonora, indicando a localização dos principais pontos críticos, possibilitando a introdução de medidas de gestão e de redução de ruídos em espaços urbanos.

Neste contexto, o objetivo deste trabalho foi avaliar a área de impacto sonoro da termoelétrica na área urbana do município de Humaitá, e assim identificar se está ou não acima dos níveis permitidos pela legislação vigente.

\section{MATERIAIS E MÉTODOS}

\section{Caracterização da Área de Estudo}

A área de estudo compreende o empreendimento termoelétrico instalado na área urbana do munícipio de Humaitá, sul do estado do Amazonas (Figura 1). Situada à margem esquerda do rio Madeira, cujas coordenadas são $7^{\circ} 30^{\prime} 56.97^{\prime \prime}$ Sul e $63^{\circ}$ 1'30.01" Oeste, e distante 591,1 km da capital amazonense.

O município de Humaitá limita-se com os municípios de Canutama, Tapauá, Manicoré e com o estado de Rondônia. Sua população, segundo estimativa do IBGE (2017) é de 53.383 habitantes, sendo que o meio urbano possui uma população de 41.748 habitantes.

Segundo a classificação de Köppen, o clima da região é do tipo Am (tropical úmido) caracterizado por temperatura média anual de $25^{\circ} \mathrm{C}$ e uma estação seca de pequena duração, entre os meses de junho e agosto. A elevada pluviosidade é um dos aspectos mais característicos da região, com valores entre 2.050 a $2.650 \mathrm{~mm}$ por ano e elevada umidade do ar, variando entre 85 e 90\% (Martins et al., 2006).

O Município de Humaitá é atendido de forma continuada por uma Usina Termelétrica de propriedade da empresa Eletrobrás Amazonas Energia, o combustível utilizado é o óleo diesel, a demanda de potência é da ordem de 8,349 MW e atualmente o sistema de distribuição é atendido por quatro alimentadores (ELETROBAS, 2018). 
$\begin{array}{llllll}\text { AVALIAÇÃO DO IMPACTO } & \text { SONORO } & \text { DA } \\ \text { TERMOELÉTRICA NA ÁREA } & \text { URBANA } & \text { DO } & \text { SE } \\ \text { MUNICÍPIO DE HUMAITÁ/AM } & \end{array}$ MUNICÍPIO DE HUMAITÁ/AM

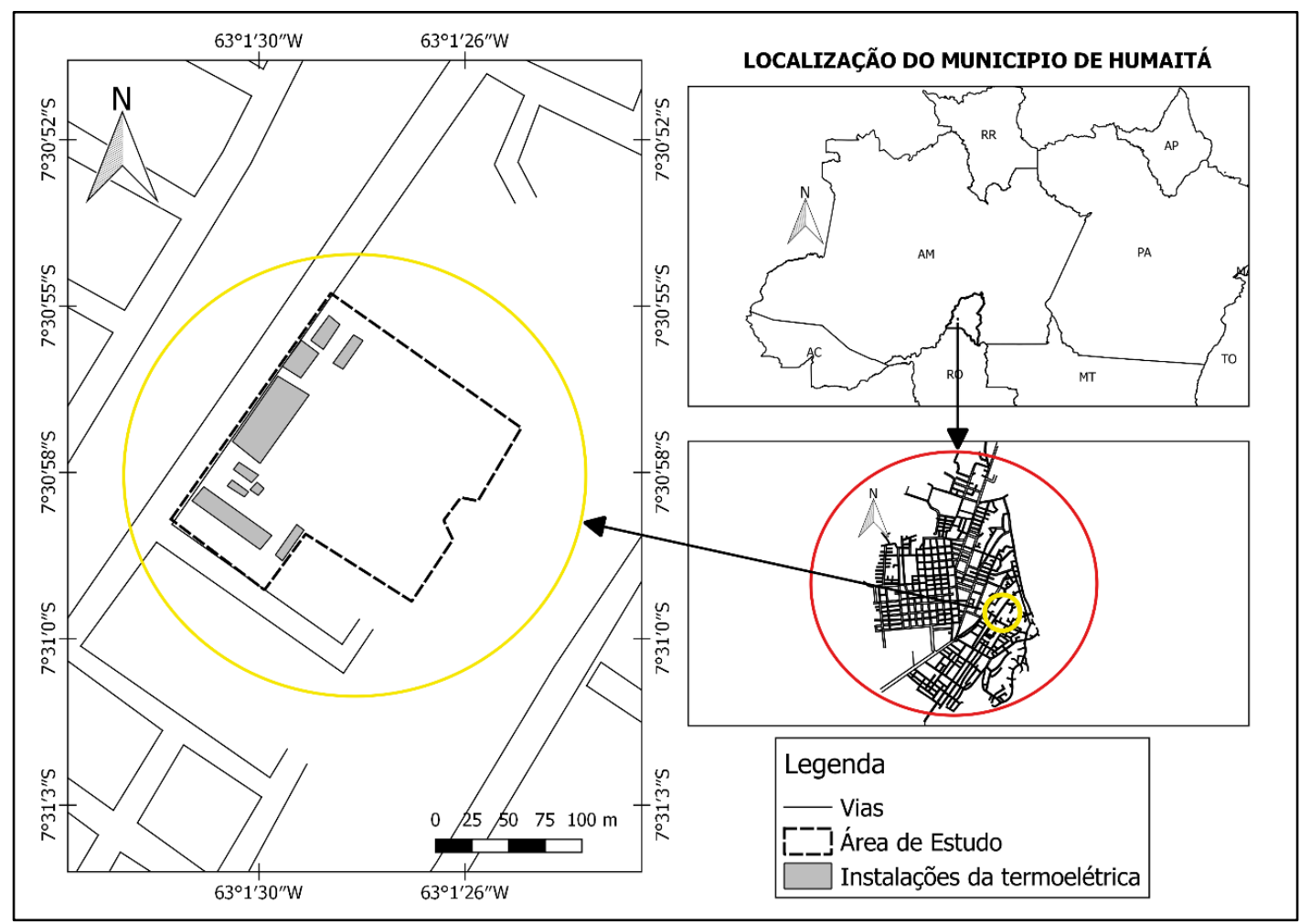

Figura 1. Localização da área de estudo. Fonte: Autores.

\section{OBTENÇÃO E PROCESSAMENTO DOS DADOS}

\section{Coleta de dados}

Para o desenvolvimento deste estudo foi realizado um levantamento do nível de ruído emitido pela termoelétrica. Para isto, foi utilizado um decibelimetro digital modelo AK824 além de um GPS portátil modelo Garmim Map 64s para coleta e espacialização dos pontos em campo.

As medidas foram efetuadas a 1,20 $\mathrm{m}$ de altura acima do solo obtidas de forma não concomitante em malha amostral com distância média a cada 30 metros ao longo das avenidas no entorno do empreendimento termelétrico.

As expedições em campo foram realizadas nos dias 09/06/2018 e 23/10/2018 entre 08:00 a 11:00 AM no primeiro dia, e de 09:00 a 12:00 AM no segundo dia. A temperatura média no horário de coleta no primeiro dia era de $29^{\circ} \mathrm{C}^{\circ}$ umidade relativa do ar de $53 \%$, ventos fracos na direção SSE, pressão de $1.006 \mathrm{hPa}$. No segundo dia a temperatura média era de $27^{\circ} \mathrm{C}$ com umidade média de $75 \%$, ventos fracos na direção E-S, pressão de $1.004 \mathrm{hPa}$ de acordo com dados do Instituto Nacional de Meteorologia - INMET (2018).

Os dados das duas campanhas foram organizados em uma planilha do Excel onde foi calculado a média simples entre os valores para a interpolação cartográfica. A Tabela 1 apresenta os pontos amostrais observados e os valores médios de ruído observado em cada ponto. 
AVALIAÇÃO DO IMPACTO
TERMOELÉTRICA NA ÁREA
MUNICÍPIO DE HUMAITÁ/AM

\section{Processamento de Dados}

Os dados obtidos em campo foram espacializados e processados no software QGIS 2.8 aonde foi realizado uma interpolação cartográfica pelo método Krigagem com uso das ferramentas do SAGA GIS.

Em seguida, foi realizado uma comparação dos valores obtidos em campo com os níveis permissíveis de ruídos estabelecidas pela NBR $n^{\circ} 10.152$. Com base na norma técnica, foi realizado uma reclassificação com uso da ferramenta r.recode no QGIS, dos níveis de ruídos, possibilitando identificar os locais que estão em desconformidade com a legislação. A Tabela 2 apresenta os níveis de ruído permito pela legislação, em função do tipo de área para o período diurno.

Tabela 1. Pontos amostrados em campo.

\begin{tabular}{|c|c|c|c|c|}
\hline Ponto & Latitude X & Longitude $Y$ & Altitude & Nível Médio do Ruído (dB) \\
\hline $\mathrm{P} 1$ & 497353 & 9169425 & 52 & 56 \\
\hline P2 & 497327 & 9169386 & 54 & 58 \\
\hline P3 & 497311 & 9169358 & 55 & 57 \\
\hline P4 & 497290 & 9169331 & 55 & 61 \\
\hline P5 & 497271 & 9169304 & 56 & 60 \\
\hline P6 & 497253 & 9169276 & 55 & 64 \\
\hline P7 & 497227 & 9169242 & 57 & 68 \\
\hline P8 & 497217 & 9169223 & 56 & 76 \\
\hline P9 & 497205 & 9169211 & 56 & 71 \\
\hline P10 & 497186 & 9169183 & 56 & 62 \\
\hline P11 & 497168 & 9169157 & 57 & 61 \\
\hline P12 & 497151 & 9169129 & 58 & 58 \\
\hline P13 & 497134 & 9169109 & 58 & 47 \\
\hline P14 & 497119 & 9169089 & 58 & 59 \\
\hline P15 & 497107 & 9169063 & 57 & 57 \\
\hline P16 & 497139 & 9169040 & 58 & 51 \\
\hline P17 & 497162 & 9169045 & 57 & 62 \\
\hline P18 & 497182 & 9169059 & 56 & 56 \\
\hline P19 & 497200 & 9169074 & 53 & 61 \\
\hline P20 & 497230 & 9169053 & 54 & 53 \\
\hline P21 & 497249 & 9169040 & 53 & 55 \\
\hline P22 & 497272 & 9169061 & 52 & 57 \\
\hline P23 & 497145 & 9169111 & 58 & 57 \\
\hline P24 & 497175 & 9169140 & 57 & 61 \\
\hline P25 & 497204 & 9169152 & 57 & 63 \\
\hline P26 & 497238 & 9169145 & 54 & 64 \\
\hline P27 & 497267 & 9169123 & 53 & 59 \\
\hline P28 & 497285 & 9169110 & 51 & 62 \\
\hline P29 & 497309 & 9169136 & 50 & 65 \\
\hline P30 & 497302 & 9169296 & 54 & 71 \\
\hline P31 & 497335 & 9169274 & 52 & 74 \\
\hline P32 & 497349 & 9169410 & 53 & 66 \\
\hline P33 & 497461 & 9169379 & 49 & 67 \\
\hline P34 & 497543 & 9169336 & 50 & 58 \\
\hline P35 & 497507 & 9169267 & 49 & 62 \\
\hline P36 & 497471 & 9169209 & 50 & 63 \\
\hline P37 & 497492 & 9169196 & 51 & 62 \\
\hline P38 & 497445 & 9169162 & 51 & 76 \\
\hline
\end{tabular}

REVISTA GEONORTE, V.9, N.33, p.141-152, 2018.

DOI: 10.21170/geonorte.2018.V.9.N.33.141.152

(ISSN 2237 - 1419) 
AVALIAÇÃO DO IMPACTO SONORO DA

TERMOELÉTRICA NA ÁREA URBANA DO MUNICÍPIO DE HUMAITÁ/AM

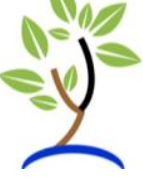

$\begin{array}{ll}\text { P39 } & 497420 \\ \text { P40 } & 497397 \\ \text { P41 } & 497372\end{array}$

9169124

50

68

P41

497372

9169094

9169034

50

66

69

Fonte: Autores.

Tabela 2. Níveis de ruído permitido pela legislação em função do tipo de área ocupada.

\begin{tabular}{|c|c|c|}
\hline Tipos de áreas & $\begin{array}{l}\text { Níveis de Ruído (dB) no } \\
\text { período diurno }\end{array}$ & Classes \\
\hline Áreas de sítios e fazendas & 40 & Classe 1 \\
\hline $\begin{array}{l}\text { Área estritamente residencial urbana ou de } \\
\text { hospitais ou de escolas }\end{array}$ & 50 & Classe 2 \\
\hline Área mista, predominantemente residencial & 55 & Classe 3 \\
\hline $\begin{array}{c}\text { Área mista, com vocação comercial e } \\
\text { administrativa }\end{array}$ & 60 & Classe 4 \\
\hline Área mista, com vocação recreacional & 65 & Classe 5 \\
\hline Área predominantemente industrial & 70 & Classe 6 \\
\hline
\end{tabular}

Fonte: NBR $n^{\circ} 10.151$

\section{RESULTADOS E DISCUSSÃO}

A partir do levantamento de dados em campo e processamento com uso do software QGIS 2.8 foi possível espacializar os níveis de ruído na área de estudo. A técnica utilizada (Krigagem) possibilitou estimar os níveis de ruído em áreas não amostradas a partir de um conjunto de pontos conhecidos.

Com base nos limites estabelecidos pela NBR $n^{\circ} 10.151$ foi elaborado mapas de classes de impacto sonoro no entorno da termoelétrica, o que possibilitou identificar a realidade que a área afetada pelo empreendimento sofre com o funcionamento do empreendimento.

Observa-se na Figura 2 a distribuição espacial dos níveis de ruídos no entorno do empreendimento termoelétrico. Os locais com os níveis de ruído mais elevado, na faixa de $69 \mathrm{~dB}$, são o da região mais próxima a termoelétrica juntamente com uma pequena porção da região situada no Sudeste da área avaliada. Essa região por sua vez, no momento da coleta de dados foi influenciada pelos altos níveis de ruídos emitidos em residências no local (música alta), o que explica o porquê dos elevados níveis de ruídos observados nessa área. Vale destacar que mesmo na ausência de obstáculos o som sofre atenuações ao se propagar livremente em consequência de um conjunto de condicionantes ambientais como absorção atmosférica, variação de temperatura, efeito do vento e dispersão das ondas com a distância percorrida (GERGES, 2000).

Por outro lado, na região sudoeste do mapa observou-se os menores níveis de ruídos na área (entre 56,00 a 59,30 dB), além de pequenas porções no extremo norte e leste da área. Os menores níveis de ruído observados nesses locais podem ter ocorrido em 
AVALIAÇÃO DO IMPACTO SONORO DA TERMOELÉTRICA NA ÁREA URBANA DO MUNICÍPIO DE HUMAITÁ/AM

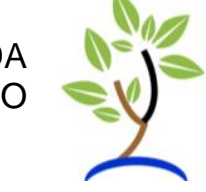

função da direção do vento, como descrito por Gerges (2000), uma vez que no local não existe obstáculos que possa conter os níveis de ruído.

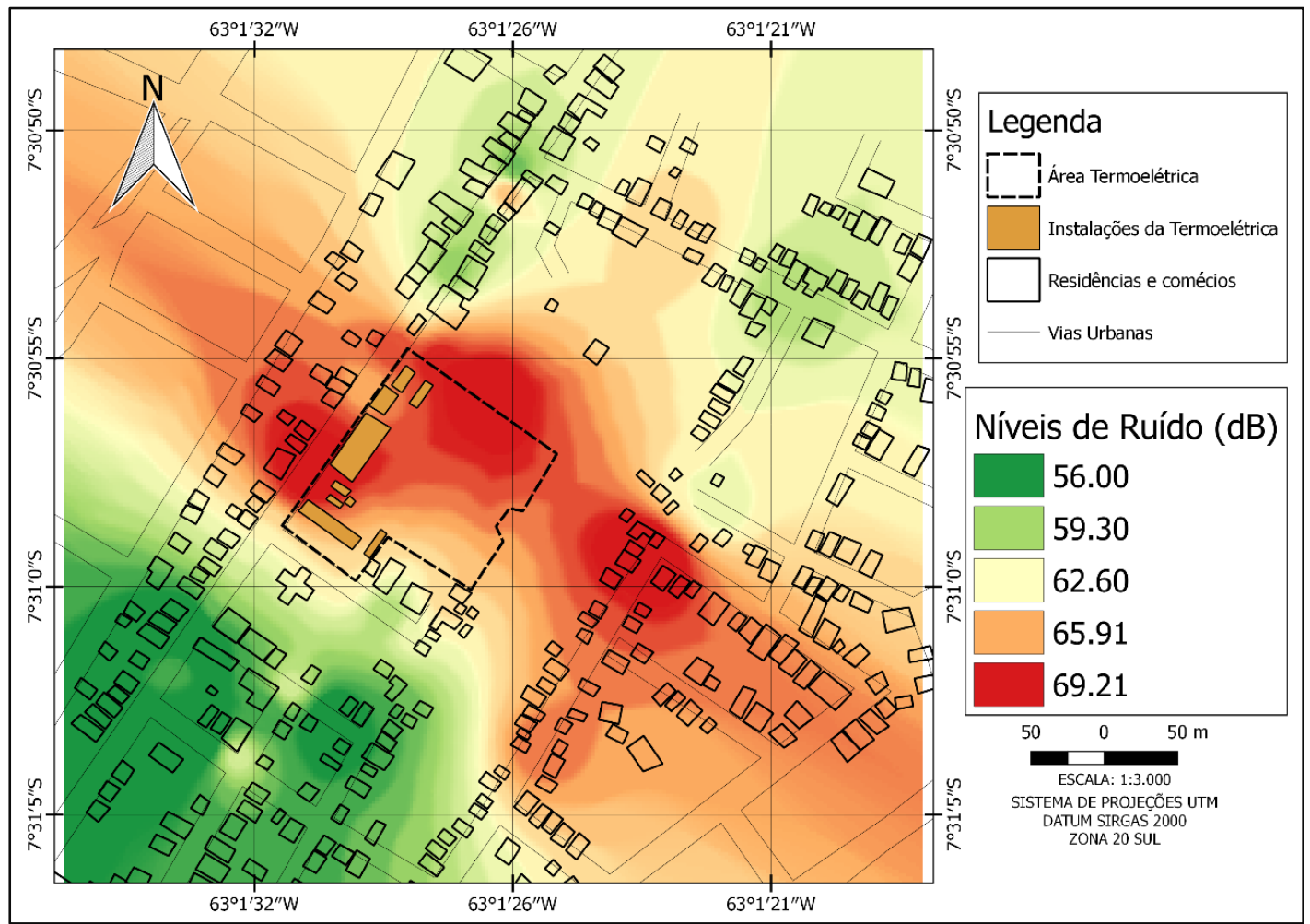

Figura 2. Espacialização do nível de ruído no entorno da termoelétrica. Fonte: Autores.

A partir da análise da Figura 3 é possível observar qual seria a classificação NCA (Nível de Critério de Avaliação) de acordo com os níveis do ruído na região. Encaixando-se assim Classe 6, Classe 5 e Classe 4. Ou seja, o local apresenta características de "área predominantemente industrial; área mista, com vocação recreacional e área mista, com vocação comercial e administrativa". No entanto toda a região estudada é considerada área mista, predominantemente residencial (classe 3), e com vocação comercial e administrativa (Classe 4). O que pela NBR $n^{\circ} 10.151$, deveria ter um nível máximo de ruído de $55 \mathrm{~dB}$ e $60 \mathrm{~dB}$ para a primeira e segunda classe.

Com esses resultados, constatou-se que dentro da área estudada existe somente uma pequena região que está em conformidade com a norma vigente, sendo essa região situada a sudoeste. Ressalta-se que este índice, $55 \mathrm{~dB}$, é superior ao sugerido por outras referências internacionais, como a Organização Mundial de Saúde (OMS, 2009).

As demais áreas não estão em concordância com a norma, apresentando assim níveis de ruído que não condizem com o aceitável de acordo com a NBR $n^{\circ} 10.151$. A existência dessas regiões que não estão em conformidade com a norma é preocupante, pois elas têm um nível de ruído que varia na faixa de 60 até $75 \mathrm{~dB}$. Vale ressaltar que com ruídos continuo nessa faixa, o organismo humano começa a sofrer impactos, sendo eles: diminuição do poder de concentração; aumento no nível de 
AVALIAÇÃO DO IMPACTO
TERMOELÉTRICA NA ANORO ÁREA
MUNICÍPIO DE HUMAITÁ/AM

cortisona no sangue; induz a liberação de endorfina tornando o organismo dependente; aumento da concentração de colesterol no sangue entre outros.

Pelo fato de não possuir zoneamento e apresentar níveis de poluição sonora considerados altos pela legislação vigente, é necessário que os órgãos responsáveis desenvolvam ações que possam solucionar ou minimizar esse impacto. É importante destacar que para a construção de qualquer empreendimento desse porte é necessário fazer-se um estudo técnico do local, para que problemas enfrentados atualmente pelos moradores da região próxima a termoelétrica não venha se repetir. Esse caso poderia ser solucionado e/ou minimizado se existisse um plano diretor municipal efetivo no município, que por sua vez tem o papel de evitar a existência de usos conflituosos do solo.

Como parte de políticas públicas voltadas amenizar os problemas referente a poluição sonora, o Plano Plurianual do município de Humaitá (Lei n 505/09 - quadriênio 2010/2013) apresentou dentro do programa de combate e controle da poluição e reciclagem dos resíduos sólidos um item referente a poluição sonora, que tinha como objetivo educar e conscientizar a população, identificar e cadastrar os atores envolvidos, controlar e combater a poluição sonora na área urbana do município.

Observa-se na Figura 4 a densidade de residências nos locais caracterizados como classe 5 e 6 (Área mista, com vocação recreacional e Área predominantemente industrial), que são áreas de alto impacto a saúde humana. Uma possível ação que poderia ser realizada com intuído de minimizar os altos níveis de ruído seria a adoção de um sistema de proteção natural constituído por arborização densa.

Como se sabe, o som é uma onda e precisa de um meio para se propagar, neste caso o ar. Desse modo, o estabelecimento de uma barreira natural constituída por árvores densas iria funcionar como uma barreira acústica, diminuindo assim o impacto sonoro no local.

No entanto, na ausência de barreiras naturais, as avenidas se tornam corredores acústicos em função do efeito de barreira causada pelas construções que bloqueiam o som, exercendo um papel de barreira acústica (Garavelli et al., 2010). 
AVALIAÇÃO DO IMPACTO SONORO TERMOELEETTRICA NA ÁREA URBANA MUNICÍPIO DE HUMAITÁ/AM
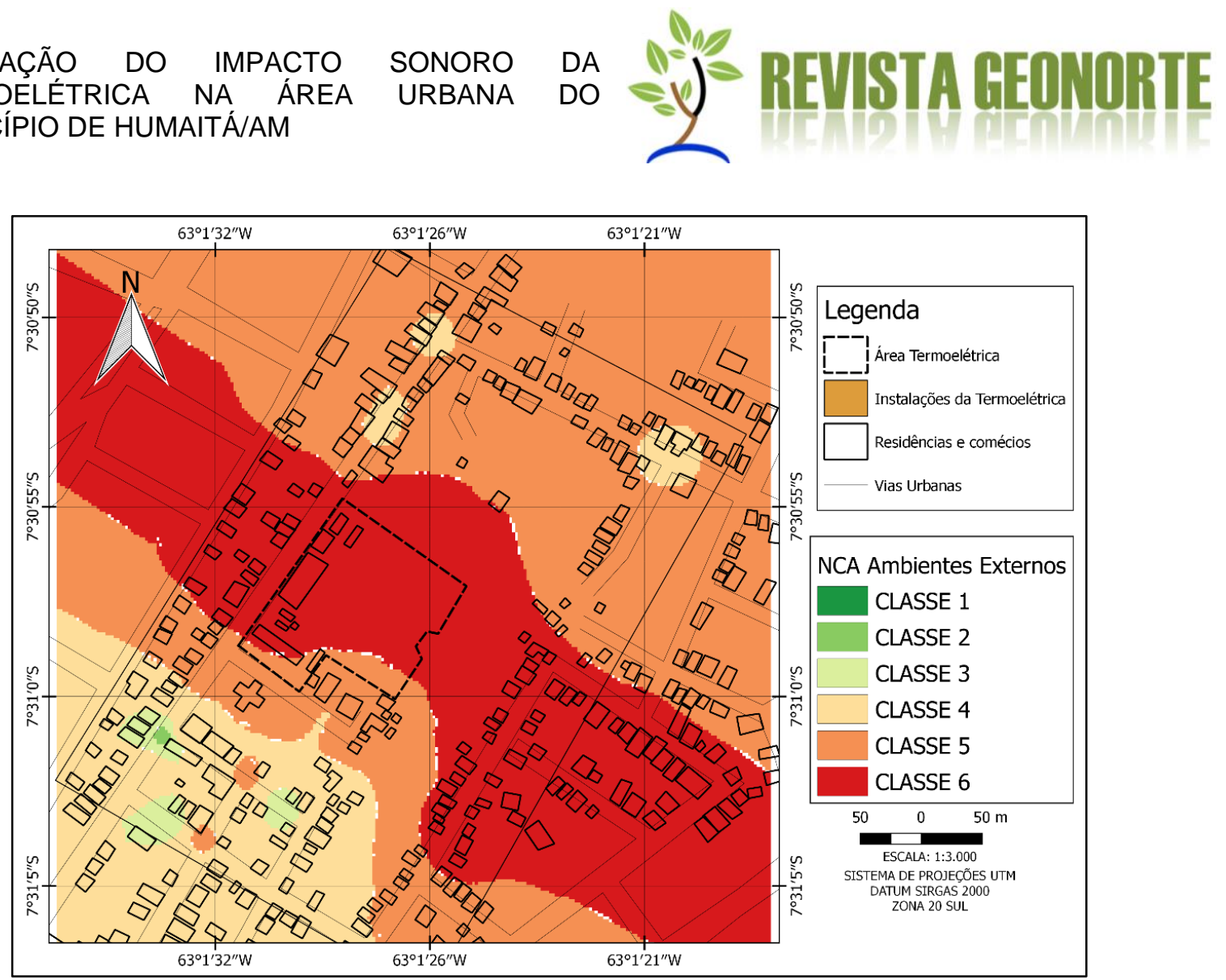
Autores.

Figura 3. Classificação dos níveis de ruído de acordo com a NBR $n^{\circ} 10151$. Fonte:

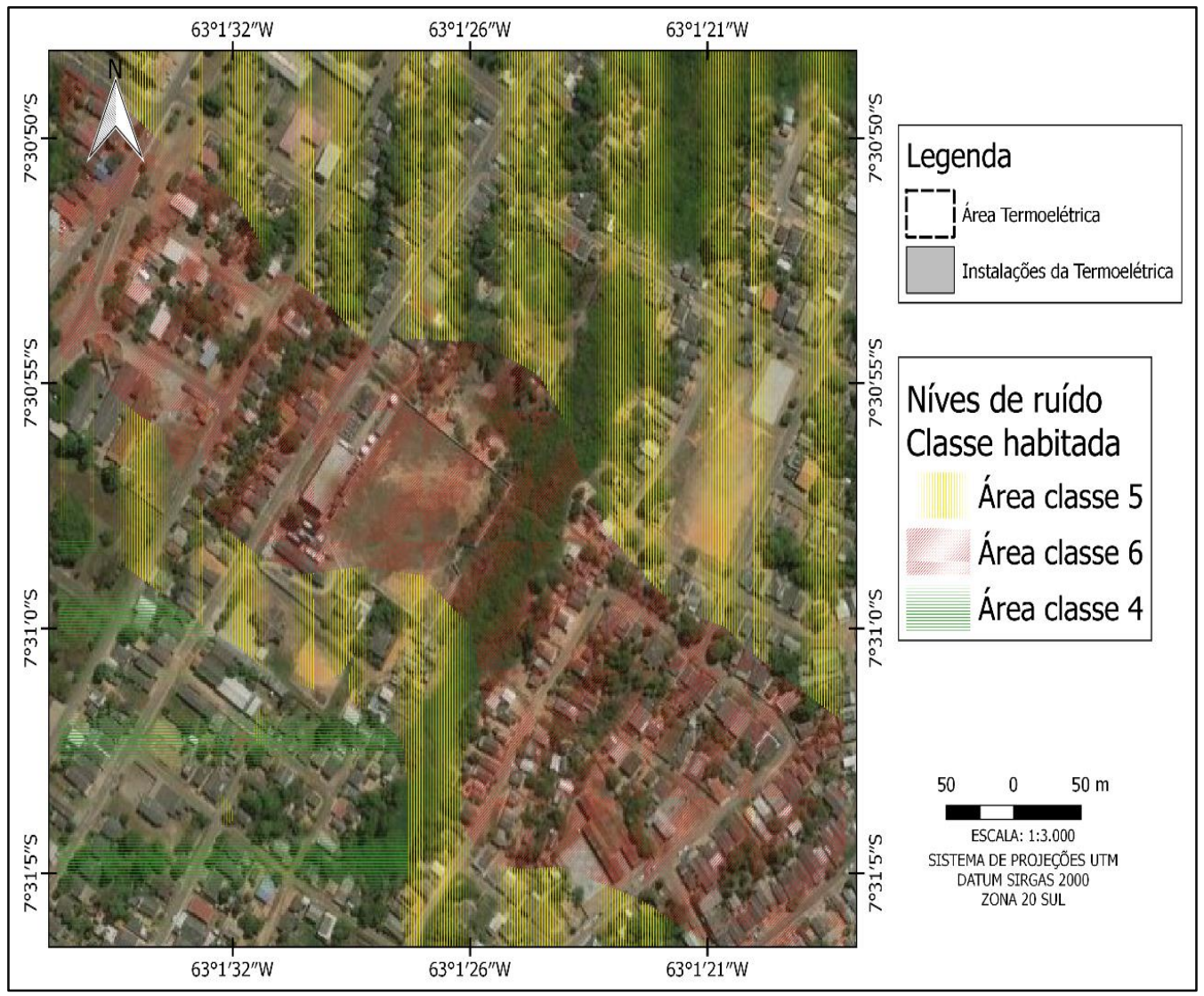

Figura 4. Níveis de ruído por áreas habitadas. Fonte: Autores. 
AVALIAÇÃO DO IMPACTO SONORO DA TERMOELÉTRICA NA ÁREA URBANA DO MUNICÍPIO DE HUMAITÁ/AM

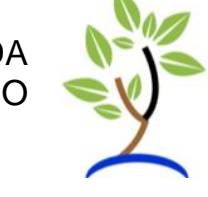

\section{CONSIDERAÇÕES FINAIS}

A partir dos dados obtidos foi possível observar que os níveis de ruídos na área de estudo estão acima dos níveis estabelecidos pela NBR n 10.151 .

A falta de zoneamento urbano adequado possibilitou a instalação do empreendimento termoelétrico no centro da cidade. E com isso os moradores da região sofrem com a poluição sonora causada pelo seu funcionamento.

Uma possível ação que pode ser adotada afim de minimizar os altos níveis de impacto sonoro diz respeito ao plantio de arvores no entorno do empreendimento. As árvores densamente plantadas podem servir como proteção natural em forma de bloqueio às ondas de som, proporcionando uma proteção efetiva contra os altos níveis de ruídos emitidos no local.

\section{AGRADECIMENTOS}

A Universidade Federal do Amazonas-UFAM pela concessão de bolsa pelo projeto PIBEX e a Secretaria Municipal de Meio Ambiente do município de Humaitá pelo empréstimo do decibelímetro para realização das medições.

\section{REFERÊNCIAS BIBLIOGRÁFICAS}

ALMEIDA, J. P.; ALEIXO, N. C. R.; NETO, J. C. A. S. Poluição Sonora no Espaço Urbano de Pauini-AM. In: Anais do VIII GeoSaúde. VIII Simpósio Nacional de Geografia da Saúde. Dourados, Mato Grosso do Sul, p. 1585-1600. 2017.

ASSOCIAÇÃO BRASILEIRA DE NORMAS TECNICAS_ABNT. NBR 10151: ACÚSTICA- avaliação do ruído em áreas habitada, visando o conforto da comunidade. Rio de Janeiro, p. p. 4. 2000.

BRESSANE, A.; MOCHIZUKI, P. S. CARAM, R. M.; ROVEDA, J. A. F. Zoneamento ambiental acústico como estratégia de gestão e controle da poluição sonora urbana. RA'E GA, v.35, p.147 - 168, 2015.

ELETROBRAS - Projeto de Referência para atendimento aos Mercados Isolados da Eletrobrás Amazonas Energia. Manaus-AM, p. 89. Disponível em: http://www.eletrobrasamazonas.com/cms/, Acesso em: 25/11/2018.

FERNANDES, D. C. Aspectos Gerais Acerca da Poluição Sonora. FÓRUM AMBIENTAL DA ALTA PAULISTA. v. 7. n. 4, p. 700-708. 2011. 
AVALIAÇÃO DO IMPACTO SONORO DA TERMOELÉTRICA NA ÁREA URBANA DO MUNICÍPIO DE HUMAITÁ/AM

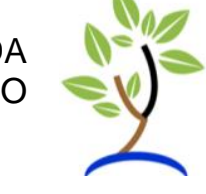

FLORIANO, C. F.; PACHECO, C. A.; ABELHA, R. M. Manual de direito ambiental e legislação aplicada. São Paulo: Max Limonad. 1997. p. 387.

FREITAS, V. P.; FREITAS, G. P. Crimes contra a natureza. São Paulo: Revista dos Tribunais, 2006.

GARAVELLI, S. L.; MORAES, A. C. M.; NASCIMENTO, J. R. R. NASCIMENTO, P. H. D. P.; MAROJA, A. M. Mapa de ruído como ferramenta de gestão da poluição sonora: estudo de caso de Águas Claras - DF. In: Anais do 4ํㅡㄹ Congresso Luso-Brasileiro para o Planejamento Urbano, Regional, Integrado, Sustentável - PLURIS, 2010, Faro, Portugal. 2010. p. 1-12.

GERGES, S. N. Y. Ruído: fundamentos e controle. 2ª ed. Florianópolis: NR Editora, 2000.

INMET - Instituto Nacional de Meteorologia. Disponível em: http://www.inmet.gov.br/portal/index.php?r=home2/index, acesso em: 12/11/2018.

INSTITUTO BRASILEIRO DE GEOGRAFIA E ESTATÍSTICA - IBGE. Disponível em: https://cidades.ibge.gov.br/brasil/am/humaita/panorama. Acesso em: jul. 2018.

MACHADO, P. A. L. Direito ambiental brasileiro. São Paulo: Malheiros, 2010.

MARCHETTI, M. C.; CARVALHO, M. S. Ruídos na cidade de Londrina - Paraná, Brasil. RA'E GA, v. 23, p. 621-651. 2011.

MARTINS, G. C.; FERREIRA, M. M.; CURI, N.; VITORINO, A. C. T.; SILVA. M. L. N. Z. Campos nativos e matas adjacentes da região de Humaitá (AM): atributos diferenciais dos solos. Ciência e Agrotecnologia, v. 30, n. 2, 2006.

OLIVEIRA, V. M. M.; MACIAL, A. B. C.; REIS, L. M. M. Poluição sonora: um estudo de caso do Parque Eólico Asa branca II, localizado no município de Parazinho-RN. Boletim de Geografia, v. 36, n. 1, p. 112-130, 2018.

ORGANIZAÇÃO MUNDIAL DE SAÚDE - OMS. Relatório de avalição sobre as condições ambientais de saúde na Europa. Disponível em: Acesso em: 11 fev. 2012

PASTORE, M. Trabalhar em local barulhento pode aumentar o risco cardíaco. Folha de S. Paulo, Equilíbrio e Saúde, 7 out. 2010. Disponível em: https://www1.folha.uol.com.br/equilibrioesaude/811203-trabalhar-em-localbarulhento-pode-aumentar-o-risco-cardiaco.shtml, Acesso em: jul.2018.

PAZ, E. C.; ZANNIN, P. H. Avaliação do ruído de tráfego noturno - estudo de caso na cidade de Curitiba, Brasil. RA'E GA, v.31, p.29-52, 2014. 
AVALIAÇÃO DO IMPACTO SONORO DA TERMOELÉTRICA NA ÁREA URBANA DO MUNICÍPIO DE HUMAITÁ/AM

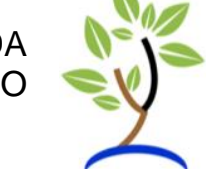

PEREIRA, J. M. N.; LAUREANO, F. V. Atividades acadêmicas e poluição sonora: análise do ruído ambiental no entorno da PUC Minas em Betim. Caderno de Geografia. V. 25. N. 44, p. 165-175. 2015.

SHOEGIMA, A. T. F. S.; FILHO, A. P. Q. Poluição sonora: estudo de caso do trânsito de veículos na subprefeitura de Pinheiros - São Paulo. Confins. n. 21. p. 1-13. 2014.

SOARES, P.; RIBEIRO, R.; SANTOS, G.; CONSTANTINI, A.; ZANNIN, P. H. T. Análise espectral do ruído entorno do campus Centro Politécnico da Universidade Federal do Paraná. RA'E GA, v.32, p.73-94, 2014.

SOUSA, R. R. Poluição Sonora na avenida ministro João Alberto na cidade de Barra do Garças-MT. InterEspaço. v. 2, n. 6, p. 198-220, 2016.

TAVARES, V. C. O processo de britagem da empresa Britamix no município de Queimadas/PB e a análise da poluição sonora. Revista Brasileira de Geografia Física v.9, n.2, P. 399-412. 2016.

WORLD HEALTH ORGANIZATION - WHO. Night noise guidelines for Europe. Copenhagen: WHO, 2009.

ZANNIN, P. H. T; CALIXTO, A.; DINIZ, F. B.; FERREIRA, J. A.; SCHULI, R. B. Incômodo causado pelo ruído urbano à população de Curitiba - PR. Revista de Saúde Pública, São Paulo, v.36, n.4, p.521-524, 2002. 